\title{
Improvisation and reciprocal design: Soundplay for dementia
}

${ }^{*}$ Gail Kenning ${ }^{\mathrm{a}, \mathrm{c}}$, Alon Ilsar ${ }^{\mathrm{a}}$, Rens Brankaert ${ }^{\mathrm{b}}$, Mark Evans ${ }^{\mathrm{a}}$

${ }^{a}$ Faculty of Arts and Socia Sciences, University of Technology Sydney;

${ }^{b}$ Industrial design systematic change group, Eindhoven University of Technology

${ }^{b}$ Ageing Futures Institute, University of New South Wales

*corresponding author gail.kenning@uts.edu.au; gail.kenning@unsw.edu.au

BIO

Provide short biographical notes on all contributors here if the journal requires them. 


\section{Improvisation and reciprocal design: Soundplay for dementia}

Research and practice is ongoing in to the affective impact of music of people living with advanced dementia and the relationship to positive wellbeing. Projects have primarily employed familiarity as a means to encourage engagement, such as using familiar tunes, songs, or instruments. This project explored the response of people living with advanced dementia to an innovative gestural electronic instrument, The Airsticks ${ }^{\mathrm{TM}}$. The engagement promoted creative musical improvisation and resulted in an highly emotive response from one particular participant and revealing the ongoing existence of a creative impulse.

Keywords: Dementia, design, improvisation, music, creativity

\section{Introduction}

The impact of music on people living with dementia has been empirically and theoretically explored. Research has shown that people in advanced stages positively respond to familiar music and may recall or affectively respond to tunes, songs and lyrics. Creative group therapy sessions often explore musicmaking with people living with dementia, where they play commonplace percussion instruments such as drums or tambourine, which may or may not be familiar to individual participants. However, the possibilities for creative sound improvisation remains under explored. The pilot project Soundplay for wellbeing introduced people living with dementia to technologies, ways of being creative with sound by working with spatially located sound, and types of electronically generated sounds, that were all unfamiliar to them. Workshops were held with people living with advanced dementia to examine their response to an innovative gestural electronic musical instrument - The Airsticks ${ }^{\mathrm{tm}}$ — which had been developed for use by professional electronic musicians. The aim was to understand whether people living with advanced dementia could engage with The Airsticks ${ }^{\mathrm{tm}}$, to what extent they would be interested in engaging creatively and improvising with sound, and what 
changes needed to be made to the hardware and software of The Airsticks ${ }^{\mathrm{tm}}$ to make them accessible and available to people living with dementia. The participants in a workshop project responded with varying degrees of interest. However, one participant showed an intense curiosity which eventuated in a deep affective response when she engaged in a spontaneous improvisation with a professional musician engaged as a researcher on the project.

\section{Background}

Research has increasingly shown how music can positively impact people living with mild cognitive impairment, limited cognitive functions, and advanced dementia (Baird \& Samson, 2015; Gold, 2013). For example, personalised playlists and soundscapes are increasingly being assembled by family members and care givers to enable people living with advanced dementia to listen to favourite or familiar songs and sounds as an activity in itself, and for use in music players embedded in tangible objects (Kenning, 2018; Treadaway \& Kenning, 2015). These sound fragments and music selected by family members and care givers are used to stimulate, excite, calm and relax, to prompt memory recall, or to elicit affective responses from people living with dementia in aged and dementia care settings. An exemplar of this type of approach is the Music and Memory program developed in Canada, and now operating worldwide, which attests to the impact that music has in improving the wellbeing of people living with dementia (http://www.MusicandMemory.org, 2011). In the context of listening to music and soundscapes, the tunes, lyrics, and songs are usually familiar to the person living with dementia, and even if they are not able to recall the music specifically, they may have an affective or implicit memory response to what they hear (Sabat, 2006). Similarly when people living with advanced dementia engage in music making, they usually engage with commonplace musical instruments, (or objects that act as substitutes), 
although all participants engaged in the improvisation or performance may not have used them before ("Drumming workshops"). Often in these types of activities there is no intent to extend the musical instruments beyond the accepted conventional use of the instrument, to explore individual creative responses or to promote improvisation.

Recent research studies and design projects have begun to explore the impact of both familiar music, ambient sound and soundscapes and the unfamiliar on people living with dementia (Houben et al., 2019) (Kenning, Brankaert, \& Houben, 2018). For example, the Everyday Sounds Of Dementia project explores sounds and soundscapes with people living with dementia and shows how technology can be used to support and extend creative exploration of sound (Brankaert \& Ouden, 2017; Kenning et al., 2018).

In design for dementia co-design approaches have been adapted to enable people living with dementia, even in advanced stages of the disease, to engage and contribute to the development of services, products and activities that can support their general health and wellbeing and contribute to quality of life (Hendriks et al,2014, Kenning, 2017, Maldonado Branco, 2017, Treadaway and Kenning 2017). Such approaches have often used visual and tactile probes in workshops environments to elicit verbal and nonverbal responses and so contribute to ongoing development. However, the aim of the Soundplay for Wellbeing project was to test out a developed prototype which was close to being a finalised project for people in the music industry — the Airsticks ${ }^{\mathrm{tm}}$ — and explore whether there was an interest in the use of the instrument, and how it could be further adapted to suit the needs of people living with advanced dementia.

\section{Methodology}

Two workshops were set up in two residential care facilities in Sydney, Australia to explore the extent to which people living with advanced dementia would be motivated to engage creatively in musical improvisation with electronically generated music using 
an unfamiliar musical instrument-The Airsticks ${ }^{\mathrm{TM}}$. A total of eleven participants took part in the workshops each with a diagnosis of dementia, as advised by the care organisation with the duty of care for them. The project used a research through design approach by using developed design prototypes, in varying degrees of finish, to assess the interest and impact by and on people living with advanced dementia (Zimmerman \& Forlizzi, 2014).

\section{The prototypes}

The main aim of the Soundplay for Wellbeing project was to investigate the response of participant in the use and creative engagement of the participants. However, as there were only two Airsticks ${ }^{\mathrm{TM}}$ available at any one time during the workshops, two Makey Makey ${ }^{\mathrm{tm}}$ prototypes were used to engage participants when the Airstick ${ }^{\mathrm{tm}}$ were in use by other participants. The Makey Makey ${ }^{\mathrm{TM}}$ prototypes were selected because they used electronic technology to support musicmaking and had generated sustained interest in earlier creative projects working with people living with advanced dementia (Kenning, 2018). In these workshops hardware and software kits were used to make a representation of a piano, and a combined piano/drumkit. Makey Makey ${ }^{\mathrm{TM}}$ is an 'off the shelf' simple circuit board acclaimed as an 'invention kit for everyone'. When used in an earlier project the Makey Makey ${ }^{\mathrm{TM}}$ ‘piano' and 'drums' gave researchers insights into the level of interest and ability participants living with advanced dementia had in engaging in creative soundplay.

The AirSticks ${ }^{\mathrm{TM}}$ is a gestural musical instrument developed for professional electronic percussionists. It was designed by drummer and electronic producer Dr Alon Ilsar and computer programmer and composer Mark Havryliv. The designers explored the many different ways that the movement could be mapped to sound. They investigated a range of approaches working within diverse collaborative musical 
performers in a range of situations to overcome 'creative paralysis'. The end result is software that allows sound to be mapped spatially accessed through geolocation and motion capture technologies embedded in gaming controllers and the custom-produced hardware, still under development. The result is a 'gestural instrument' that converts the physical movement of the user, through a mapping process using computer software, into data and sound.

The range of sounds available through The Airsticks ${ }^{\mathrm{TM}}$ is vast. The software provides access to a wide range of instrument sounds (drums, harp, bells, etc), it can be programmed to recreate ambient sounds such as church bells, wind, water, or birds, or play a personalised musical playlist of songs. All of the sound elements can be 'positioned' in space and 'found' by pointing the hardware in different directions (up, down, left, right, and everything in between).

\section{Method}

Before attendees arrived at the workshop tables and chairs were located in each corner of the room at 'sound stations'. On two tables there were a set of Airsticks' ${ }^{\mathrm{TM}}$, consisting of the prototype Hydra Razor gaming controllers hardware linked to a computer loaded with The Airsticks ${ }^{\mathrm{TM}}$ custome designed spatial sound software and a speaker. On the other two tables was a Makey Makey ${ }^{\mathrm{tm}}$ piano and a Maley Makey ${ }^{\mathrm{tm}}$ piono/drum kit. These consisted of conductive metal tape to indicate piano keys, placed on a sheet of acrylic. The metal tape was then connected to the Makey Makey ${ }^{\mathrm{tm}}$ circuit board connected to a computer and speaker, loaded with the Makey Makey ${ }^{\mathrm{tm}}$ music software. Researchers focused one-on-one with participants as they engaged with each of the sound stations. 


\section{Findings}

There were a total of eleven participants in the study who engaged with the Airsticks ${ }^{\mathrm{tm}}$ and the Makey Makey ${ }^{\mathrm{tm}}$. However, this paper will primarily focus on the response of one participant, 'Violet'. 'Violet' was a participant in the second workshop, in the second aged care facility visited. She was brought into the workshop room by a carer who introduced her to the researchers, along with another participant, who was introduced as her best friend who she had known since earl childhood. She was small and looked frail and was not able to speak. She smiled constantly and laughed often when she was spoken to. She was taken one of the sound stations with the Airsticks ${ }^{\mathrm{tm}}$. The software had been programmed to play a range of musical instrument that were clearly distinguishable (harp, drums, and bells). A games controller was placed in her hand and she was shown how if she moved the controller the sounds playing through the speaker, via the computer changed. Violet engaged immediately holding on to the game controller and moving it in the way she had been shown. She was accompanied by one of the researchers who sat alongside. As she engaged with the sounds of a harp she began to sing. The words of the song, or the tune being sung were not clear or coherent, but she put a great deal of energy into the process moving her hand holding the games controller from side to side. The researcher alongside copied her responses and also began to sing and hum. The continued in this way for a sustained period of time. Violet showed no sign of tiring and laughed frequently.

Violet was taken to each of the sound stations where the Makey Makey ${ }^{\mathrm{tm}}$ equipment was located. Again she engaged with great gusto, laughing, smiling, and playing the 'piano' and the 'piano/drums', to such an extent that wear and tear was beginning to show on both as the metallic tape began to wear thin.

Towards the end of the workshop Violet was taken to the soundstation where another Airsticks ${ }^{\mathrm{tm}}$ were located. The software at this station had been set up to play excerpts of 
music in the form of a spatialised playlist. By pointing the Aisrsticks ${ }^{\mathrm{tm}}$ up and to the right rock $\mathrm{n}$ roll music played, pointing down to the left played Bach. Other accessible music included the Beatles, and Johnny B Good. As Violet sat down to engage with the Airsticks ${ }^{\mathrm{TM}}$, she understood how to use the games controller. But because she had a tendency to engage with a flourish and move her arms and the controller often, Violet 'played' small fragments of the programmed songs, which became incoherent. It was difficult to recognise how the sounds related to the movement of the body. However, this version of the software had worked particularly well for another participant whose movement was slower and physical dexterity more limited. It was apparent that this version of the software and sounds selected did not work for Violet.

At this point Violet was accompanied by a researcher who was a professional musician and the inventor of The Airsticks ${ }^{\mathrm{TM}}$. Recognising the inappropriateness of this sound track for violet, he loaded a soundscape that had been created for an international conference presentation to show the range of possibilities offered by the Airsticks ${ }^{\mathrm{tm}}$. The soundscape provided access to a range of instruments such as gamelan, xylophone, drums, harp, which could all be played spontaneously (the playlist of songs and sounds were removed. The researcher sat alongside her, placed a controller in her hand, picked up the second controller and began to make broad strokes in space, with it. Violet copied. As they sat together she began to copy his movements and recognise how the sound changed accordingly. This process continued for more than fifteen minutes. Their movement were synchronous and asynchronous as they engaged together. Throughout this time Violet had been singing along. Her words were not coherent and the singing was akin to a wailing (but did not signal any stress). The researcher began to slowly place the controller down seemingly signalling the end of the session. Violet began to follow suit and then stopped. She then lifted the controller and began to explore the 
soundscape alone. The wailing continued and became more emotive. The sound coming from her was melancholic. Violets face was not smiling or laughing as it had been, but neither was there any sign of distress. Violet wiped a tear from her eye and continued to make electronic musical sounds. The researcher, who had led the initial engagement now joined in again, but this time following Violet's movements and lead. They improvised together for in excess of 25 minutes.

As the improvisation came to an end there was a short silence when all three researchers, the carers in the room and Violet stopped. She appeared happy and tired. The carer suggested that it was time for her to go. Violet's friend, who came into the room with her began to talk to her and comment on her playing. Violet seemed to respond, but her words remained incoherent. She was laughing as she left.

\section{Discussion}

The Airsticks ${ }^{\mathrm{tm}}$ had not been designed with people living with dementia in mind. They had been developed to support musical creativity for professional musicians. After their development they had been trialled with a range of people with access needs including people with autism and paraplegia to promote inclusive creative engagement. The decision to engage with people living with dementia came about due to the recognition of the creative possibilities that The Airsticks ${ }^{\mathrm{TM}}$ offered and the opportunity for creative sound researchers and researchers working with deign for dementia to collaborate to explore the potential in this area. It was important that the engagement with people living with dementia began before The Airsticks ${ }^{\mathrm{tm}}$ were finalised as a product. This allowed for changes to be made to the hardware, or for alternative versions of the hardware to be produced specifically for this population. In addition, it was important to examine the response of people living with dementia to The Airsticks ${ }^{\mathrm{tm}}$ in context, and to establish a framework for the types of soundscapes designed in the software that 
would have most impact.

\section{Conclusion}

The Soundplay for Wellbeing project had not begun as a design project from the outset.

It came about because researchers were able to engage and explore cross-disciplinary possibilities for creative systems, processes and objects that were already in production. By engaging with the developed prototypes for creative sound improvisation in the aged and dementia care environment directly with people living with advanced dementia, it became apparent that the creative impulse is retained into the advanced stages of the disease, and that technology use and lack of familiarity with sounds or instruments was not necessarily off putting to people living with dementia. The Airsticks ${ }^{\text {tm }}$ revealed the creative potential and drive of people living with dementia, and what can be achieved through collaborative engagement, and being willing to work across disicplines.

Figure 1. Type your caption here. Obtain permission and include the acknowledgement required by the copyright holder if a figure is being reproduced from another source.

\section{References}

“Drumming workshops”. Drumming workshops music to residents' ears. Aged Care Guide. Retrieved from https://www.agedcareguide.com.au/talking-agedcare/drumming-workshops-music-to-residents-ears

Brankaert, R., \& Ouden, E. d. (2017). The Design-Driven Living Lab: A New Approach to Exploring Solutions to Complex Societal Challenges. Technology Innovation Management Review. Retrieved from https://timreview.ca/article/1049

Houben, M., Brankaert, R., Bakker, S., Kenning, G., Bongers, I., \& Eggen, B. (2019). Foregrounding Everyday Sounds in Dementia. Paper presented at the DIS 2019, San Diego.

http://www.MusicandMemory.org (Producer). (2011). Alive Inside Film of Music and Memory Project - Henry's Story. [Video] Retrieved from https://www.youtube.com/watch?v=5FWn4JB2YLU

Kenning, G. (2018). Reciprocal design: inclusive design approaches for people with late stage dementia. Design for Health, 2(1), 1-21. doi:10.1080/24735132.2018.1453638 
Kenning, G., Brankaert, R., \& Houben, M. (2018). Exploring your Soundscape Kenning, Brankaert \& Houben 2018. Paper presented at the Dementia Lab, Newcastle, UK.

Sabat, S. R. (2006). Implicit memory and people with Alzheimer's disease: Implications for caregiving. American journal of Alzheimer's disease and other dementias, 21(1), 11-14. doi:http://dx.doi.org/10.1177/153331750602100113

Treadaway, C., \& Kenning, G. (2015). Sensor e-Textiles: person centred co-design for people with later stage dementia. Working with older people, 20(2), 76-85.

Zimmerman, J., \& Forlizzi, J. (2014). Research Through Design in HCI. In O. J. \& K. W (Eds.), Ways of Knowing in HCI. New York, NY: Springer. 